\title{
Performance of Silicon Nanowire Solar Cells with Phosphorus-Diffused Emitters
}

\author{
Lingsheng Zeng, Xuegong Yu, Yangang Han, and Deren Yang \\ State Key Laboratory of Silicon Materials, Department of Materials Science and Engineering, Zhejiang University, \\ 310027 Hangzhou, China \\ Correspondence should be addressed to Xuegong Yu, yuxuegong@zju.edu.cn
}

Received 27 April 2012; Revised 11 June 2012; Accepted 29 June 2012

Academic Editor: Xiaodong Pi

Copyright ( $\odot 2012$ Lingsheng Zeng et al. This is an open access article distributed under the Creative Commons Attribution License, which permits unrestricted use, distribution, and reproduction in any medium, provided the original work is properly cited.

\begin{abstract}
Vertical silicon nanowire ( $\mathrm{Si}$ NW) arrays on a Si (100) substrate have been prepared by using a low-cost and facile Ag-assisted chemical etching technique. The reflectance of Si NW arrays is very low $(<1 \%)$ in the spectral range from 400 to $1000 \mathrm{~nm}$. By phosphorus diffusion into Si NW arrays to fabricate solar cells, the power conversion efficiency of $8.84 \%$ has been achieved. This power conversion efficiency is much higher than that of the planar cell with the similar celling technology. It is found that the efficiency of Si NW solar cells is intimately associated with their excellent antireflection property. The surface recombination of Si NWs is the main obstacle for the improvement of solar cell efficiency. The current results are helpful to the advancement of the application of Si NWs in photovoltaics.
\end{abstract}

\section{Introduction}

Silicon nanowires (Si NWs) have attracted much attention for photovoltaic applications because of their unique optical and electrical properties compared to bulk silicon [14]. It is known that Si NW arrays demonstrate excellent antireflection (AR) properties due to their broadband optical absorption by multiple scattering incidents [5-7], and therefore can be used as solar cell absorbers for trapping light [812]. Si NWs can be prepared by various methods, including chemical vapor deposition (CVD) $[13,14]$, physical vapor deposition (PVD) [15], and reactive ion etching (RIE) combined with lithography techniques [16, 17]. Among these, the metal-assisted chemical etching (MACE) technique [18-22] is more facile and more economical to fabricate Si NW arrays since it avoids high temperature or high vacuum. Thus, solar cells based on Si NW arrays fabricated by MACE have been widely investigated [8-12]. Zhu's group fabricated Si NW solar cells based on single-crystal Si substrate and polycrystalline Si substrate. They obtained the power conversion efficiency $(\eta)$ of $9.31 \%$ and $4.73 \%$ [8]. Later on, they fabricated solar cells based on slantingly aligned Si NWs on a Si (111) wafer and obtained improved solar cell performance [9]. Using a PSG-doped Si NW arrays as the $\mathrm{n}+$ emitters and a screen-printing technique to fabricate front electrodes, the efficiency of Si NW solar cells has fallen in the range from $3.55 \%$ to $16 \%$ [12]. All these results show that despite the excellent AR property of Si NWs, the efficiency of solar cells based on Si NWs is much lower than that of conventional silicon solar cells. The main problem is the high series resistance induced by the loose contact between the electrodes and Si NW arrays.

In this work, the solar cells based on $\mathrm{Si} \mathrm{NW}$ arrays have been fabricated. The phosphorus diffusion is used to form the emitters, and the metal electrodes are evaporated on the surrounding region of Si NWs with a flat surface to avoid high series resistance. It is found that the performance of Si NW arrays-based solar cells is much better than that of the solar cells based on the planar silicon due to the excellent AR property of Si NWs.

\section{Experiment Details}

The starting materials are p-type $<100>$ Czochralski $(\mathrm{CZ})$ silicon wafers with a resistivity of $3 \Omega \cdot \mathrm{cm}$. After cleaning, 
the electrical tape was used to cover the back and edge of the cleaned substrates, leaving an area of $1 \times 1 \mathrm{~cm}^{2}$ at the sample center. Subsequently, the samples were immersed in an aqueous solution of $4.6 \mathrm{M} \mathrm{HF}(40 \mathrm{wt} \%)$ and $0.005 \mathrm{M}$ $\mathrm{AgNO}_{3}$ for $60 \mathrm{~s}$ to form $\mathrm{Ag}$ nanoparticle netlike films. These Ag-deposited wafers were etched to form the Si NWs in the mixture of $4 \mathrm{M} \mathrm{HF}(40 \mathrm{wt} \%)$ and $0.2 \mathrm{M} \mathrm{H}_{2} \mathrm{O}_{2}$ (30 wt $\%$ ) solution for different time. The morphology and structure of Si NW arrays were characterized by a field-emission scanning electron microscope (SEM) (Model HITACHI S4800) and a transmission electron microscope (TEM) (Model PHILIPS $\mathrm{cm} 200)$. Optical reflectance spectra were measured with a hitachi U-4100 UV-VIS-NIR spectrophotometer. After removing the Ag nanoparticles at the sample surface with nitric acid $\left(65 \mathrm{w} \% \mathrm{HNO}_{3}\right)$, the samples were fabricated into solar cells. A standard sample without Si NWs was used as the reference. By spinning liquid $\mathrm{POCl}_{3}$ source on the sample surface, the diffusion annealing at $900^{\circ} \mathrm{C}$ for $20 \mathrm{~min}$ is used to form a spatially uniform $n$-emitter. The parasitic layer was removed in a diluted hydrofluoric acid solution. The front metal contacts were made by Ag thermal evaporation through a mask. The ohmic contact was formed by scratching InGa alloy at the sample backside. The schematic process for the Si NW solar cells is present in Figure 1.

\section{Results and Discussion}

Figure 2(a) shows the planar image of Ag nanoparticles deposited on (100) silicon substrates via the electroless metal deposition method. It is obvious that Ag nanoparticles have formed a network. Figure 2(b) demonstrates the plan-view micrograph of the Si NWs sample after etching for $20 \mathrm{~s}$ in aqueous $\mathrm{H}_{2} \mathrm{O}_{2} / \mathrm{HF}$ solution. It can be seen that some areas of $\mathrm{Ag}$ are caved in, and the silicon areas protrude outward from the interspaces among the Ag nanoparticles. It indicates that the silicon parts under the Ag nanoparticles are etched off and then the shallow pits form due to the catalytic role of $\mathrm{Ag}$, and the silicon uncovered with $\mathrm{Ag}$ remains almost unchanged. After etching for a longer time, the Si NWs can be created as the Ag nanoparticles continue to sink. Figures 2(c) and 2(d) show the planar and the cross-sectional views, respectively, of the Si NW arrays. As can be seen from the SEM micrographs, these Si nanowires are tangled with each other and hold together in bundles. This phenomenon could be caused by capillary action during the drying process due to the high aspect ratio of silicon nanowires. The diameter of silicon nanowires generally ranges from 40 to $200 \mathrm{~nm}$. Note that the silver particles could be found to lie at the bottom of the Si NWs, as shown in Figure 2(e). Figure 2(f) shows the TEM micrograph of a Si NW. It indicates that the diameter of individual nanowire is roughly uniform.

Figures 3(a)-3(e) demonstrates the cross-sectional SEM micrographs of Si NW arrays with different length fabricated at $0.2 \mathrm{M} \mathrm{H}_{2} \mathrm{O}_{2}$ and room temperature for $30 \mathrm{~s}, 60 \mathrm{~s}, 90 \mathrm{~s}$, $120 \mathrm{~s}$, and $150 \mathrm{~s}$, respectively. The SEM observation clearly revealed that the lengths of the produced Si NWs increased with the etching time, ranging from $340 \mathrm{~nm}$ to $1700 \mathrm{~nm}$,

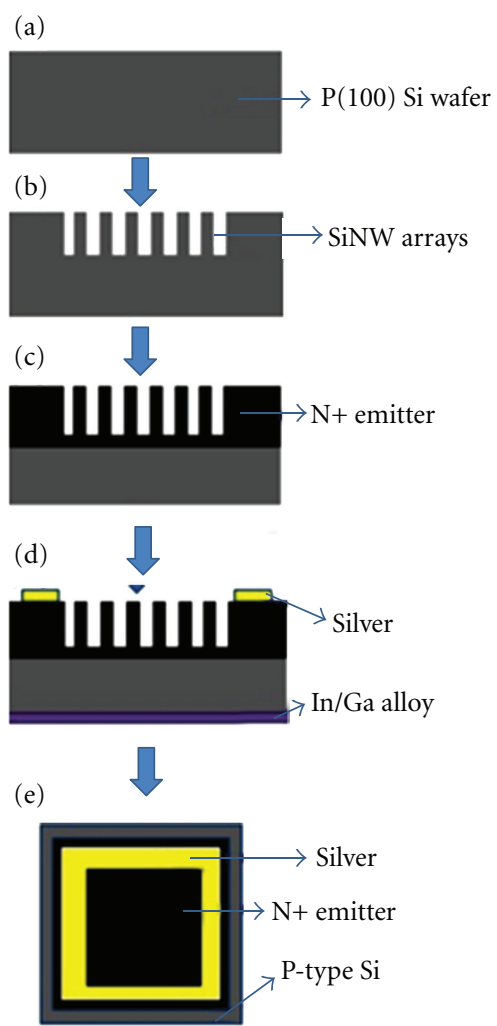

Figure 1: Schematic illustration of the fabrication process for preparing Si NW arrays-based solar cells. (a) Initial p-type silicon wafer. (b) Formation of Vertical Si NW arrays on the wafer. (c) Formation of a spatially uniform n-type emitter by phosphorus diffusion. (d) Formation of electrode on the rear and front surfaces. (e) Planar schematic of the device.

which indicates that the length of the Si NWs can effectively be tailored by prolonging the etching time. Figure 3(f) shows the Si NW length as a function of the etching time. An excellent linear behavior can be obtained. The etching rate can be evaluated to be about $11.6 \mathrm{~nm} / \mathrm{min}$.

Figure 4 shows the reflectance of Si NWs and polished wafer as a function of light wavelength. Note that the polished Si wafer has the reflectance of 35\% for sun light. It can be seen that the as-grown Si NW arrays exhibit not only a large suppression of the reflectance over the entire light wavelength range, but also a very different reflection behavior from polished Si. The reflectance decreases with the wavelength increasing. The reflectance is smaller than $18 \%$, $9 \%, 5 \%, 2 \%$, and $1 \%$ at the nanowires length of $340 \mathrm{~nm}$, $542 \mathrm{~nm}, 908 \mathrm{~nm}, 1460 \mathrm{~nm}$, and $1700 \mathrm{~nm}$, respectively. This can be attributed to the three important properties of $\mathrm{Si}$ NW arrays. One is the extremely high surface area of the Si NW arrays. The second is the suppression of the reflectance over a wide-spectral bandwidth due to the subwavelengthstructured (SWS) surface of the Si NW arrays. The third is a gradual change in the refractive index with depth due to a porosity gradient throughout the Si NW arrays which closely resembles a multi-antireflection layer coating $[8,12]$. It should also be mentioned that the interference 

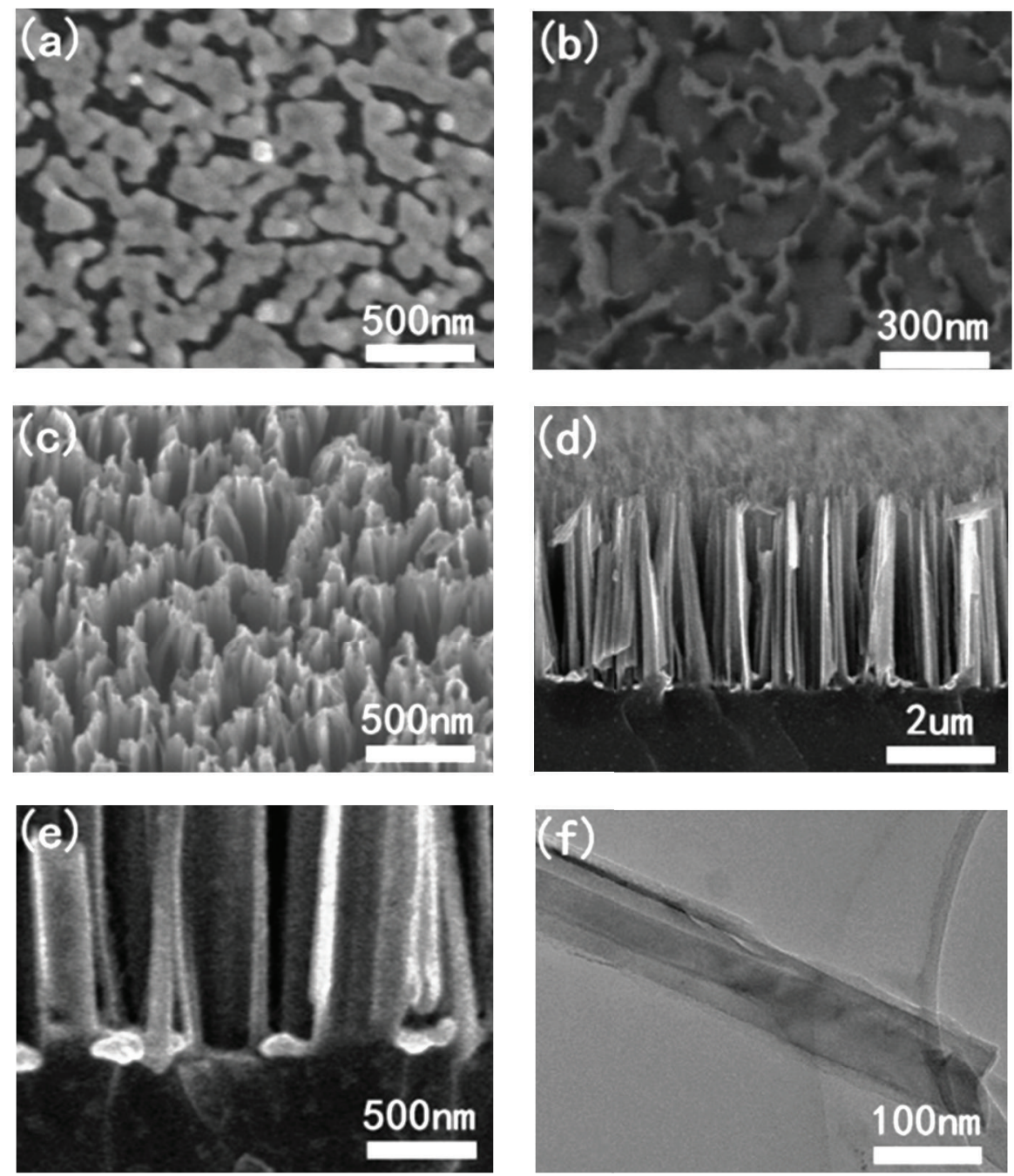

Figure 2: (a) Planar image of Ag nanoparticle netlike films deposited on (100) silicon substrates. (b) The image of the planar area of the sample etched for $20 \mathrm{~s}$ in aqueous $\mathrm{H}_{2} \mathrm{O}_{2} / \mathrm{HF}$ solution. (c) Planar image of as-prepared Si NW. (d) Cross-sectional image of as-prepared Si NW. (e) Enlarged cross-sectional image of the bottom of the arrays. (f) TEM image of individual as-prepared Si NWs.

peaks in the reflectance spectra of the Si NW arrays are related to the periodic nanostructure nature to some extent.

Figure 5 shows the illuminated I-V characteristics of the referenced cell and the Si NW cell with the Si NW length of $1700 \mathrm{~nm}$. Both kinds of solar cells exhibit the diode characteristics. Note that the referenced cell has an energy conversion efficiency $(\eta)$ of $5.65 \%$. The open-circuit voltage $\left(V_{\mathrm{oc}}\right)$, the short-circuit current density $\left(J_{\mathrm{sc}}\right)$, and the fill factor (FF) are $500 \mathrm{mV}, 19.53 \mathrm{~mA} / \mathrm{cm}^{2}$, and 0.578 . However, the performance of the $\mathrm{Si} \mathrm{NW}$ cells has been improved remarkably, with a better parameters of $\eta=8.84 \%, V_{\mathrm{oc}}=$ $500 \mathrm{mV}, J_{\mathrm{sc}}=33.40 \mathrm{~mA} / \mathrm{cm}^{2}$, and $\mathrm{FF}=0.529$. The values of $\eta$ and $J_{\text {sc }}$ of the Si NW cell are enhanced by $56 \%$ and $71 \%$, respectively, while the value of $V_{\mathrm{oc}}$ is almost the same as that of reference sample. It is obvious that the enhancement of $\eta$ mainly originates from the increase of $J_{\mathrm{sc}}$, which attributes to the strong light trapping of Si NWs, compared with the referenced cell.
In order to present a further verification, the external quantum efficiency (EQE) and internal quantum efficiency (IQE) are measured in the light wavelength range of 300 $1100 \mathrm{~nm}$, see Figure 6. Note that the IQE spectra is derived from $\mathrm{EQE}$ by $\mathrm{IQE}=\mathrm{EQE} /(1-R)$, where $R$ represents the reflectance of solar cell. From Figure 6(a), it can be seen that the EQE of the Si NW cells is much higher than that of the referenced cell, consistent with the value of $J_{\mathrm{sc}}$. Compared with IQE at the long wavelength demonstrated in the Figure 6(b), the IQE at the short wavelength are much lower for both of cells. This suggests that the surface recombination for photogenerated minority carriers is quite heavy for both kinds of cells. The IQEs of the Si NW cell are higher than that of the referenced cell in the long wavelength range, which means that the cell has a higher collection efficiency of minority carriers induced by long wavelength light.

Even though the Si NW arrays have an excellent AR property, the photovoltaic conversion efficiency is still much 


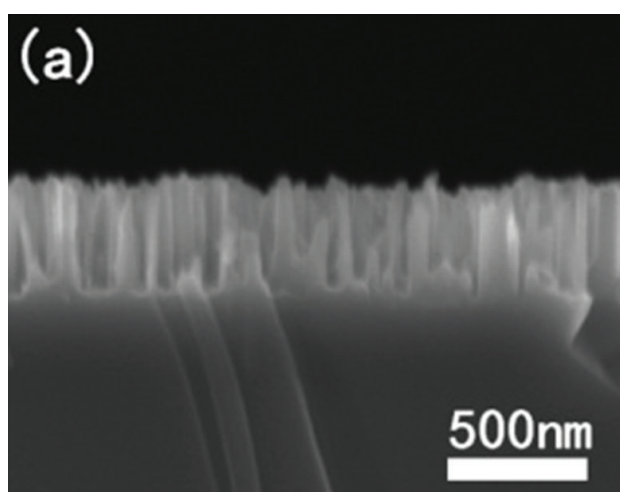

(a)

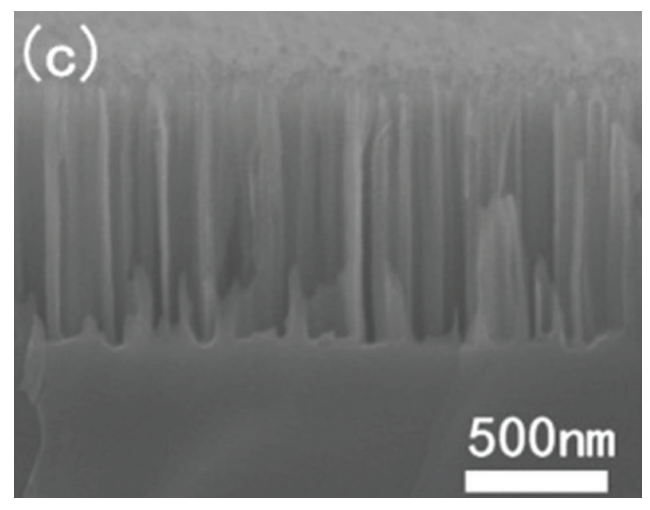

(c)

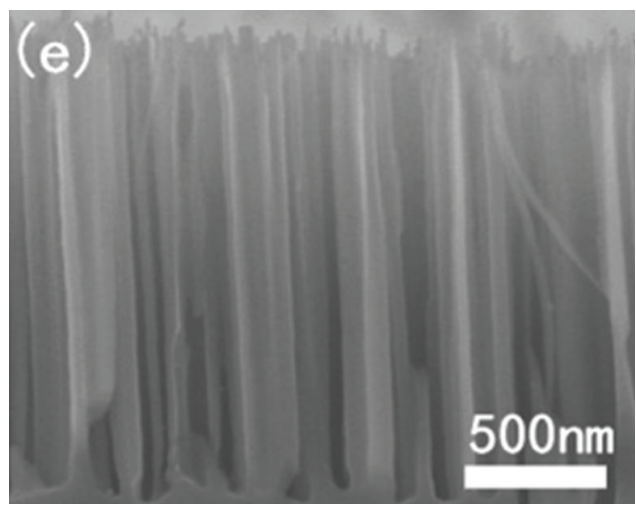

(e)

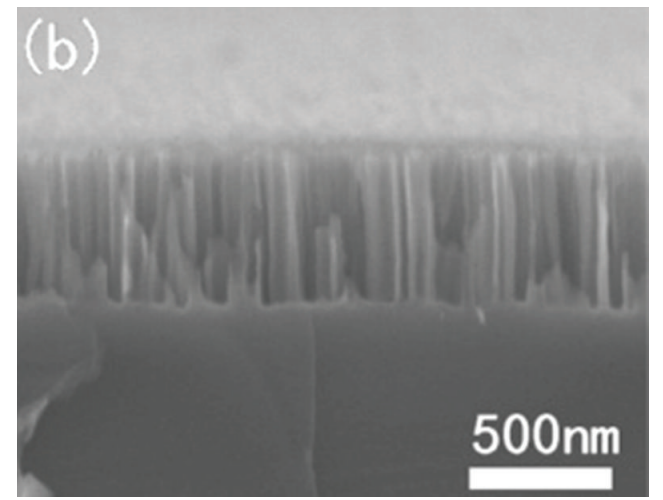

(b)

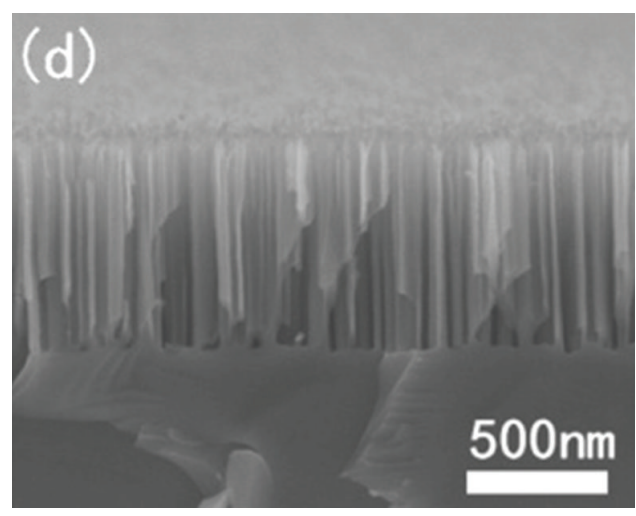

(d)

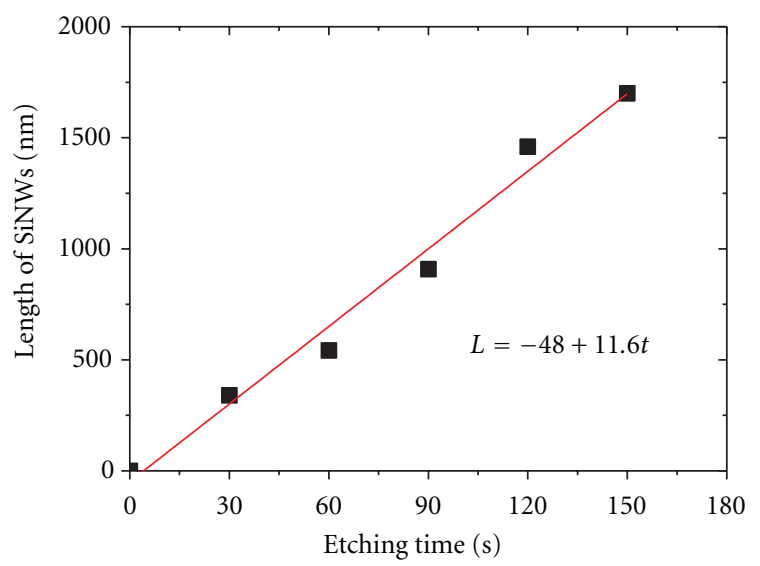

- Exp.

Linear fit

(f)

Figure 3: Cross-sectional images and length of Si NWs etched for different time. (a) $30 \mathrm{~s}$; (b) $60 \mathrm{~s}$; (c) $90 \mathrm{~s}$; (d) $120 \mathrm{~s}$; (e) $150 \mathrm{~s}$; (f) length of the Si NWs $(L)$ versus etching time $(t)$ curve.

lower than that of the conventional solar cell. One of the main reasons still lies in the ultrahigh surface area of Si NWs with numerous surface defects and dangling bonds which will accelerate the surface recombination of photogenerated minority carriers. The other is lower carriers collection efficiency of the metal electrode around the area of cell than the metal grid electrode, which increases the diffusion length of photogenerated minority carriers before they are collected although it reduces the contact resistance. Therefore, good surface passivation and optimized electrode design are required to further improve the performance of Si NW array-based solar cell. In addition, some other 


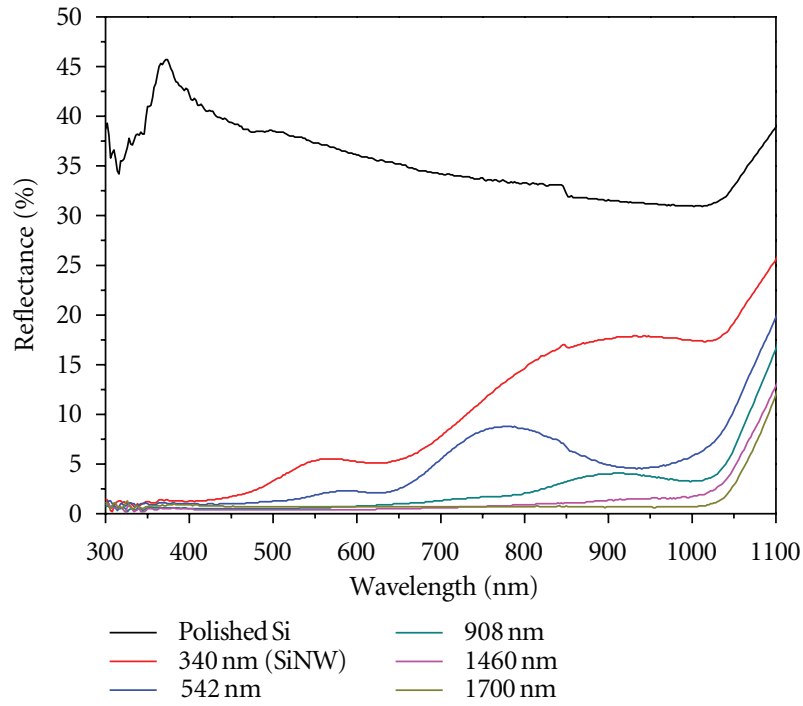

FIgURE 4: Reflectance of polished silicon and Si NW arrays of various length.

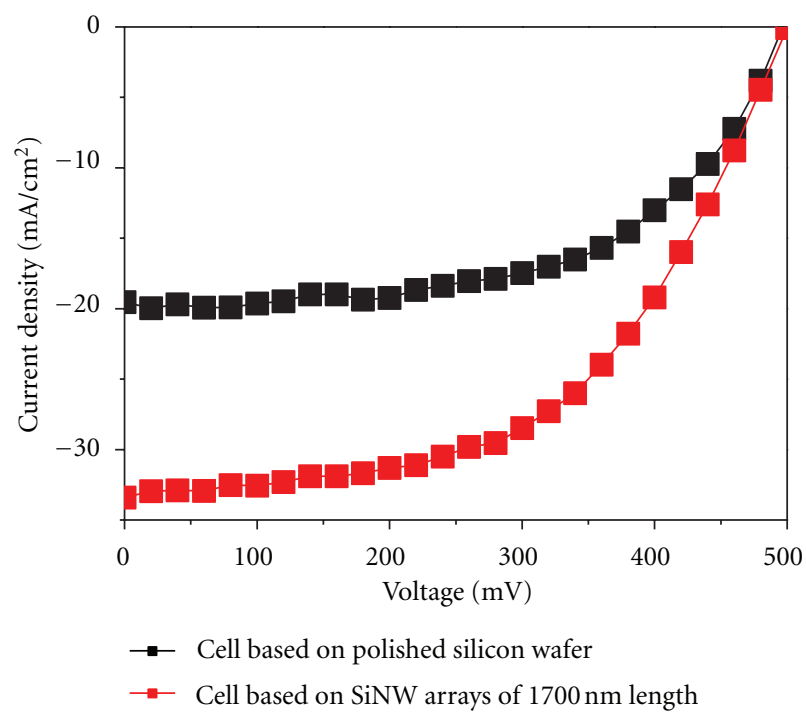

FIGURE 5: Illuminated current-voltage plot of control cell based on polished silicon wafer and Si NW arrays-based solar cells (of $1700 \mathrm{~nm}$ length).

parameters, such as Si NW arrays morphology, phosphorus diffusion, and rear electrode fabrication, should also be optimized for a higher efficiency of solar cells.

\section{Conclusions}

The $1 \times 1 \mathrm{~cm}^{2}$ Si NW arrys on (100) Si substrate has been fabricated through a low-cost and facile Ag-assisted chemical etching technique. The lengths of the synthesized Si nanowires were found to increase linearly with etching time for silicon substrates and the Si NW arrays of longer length

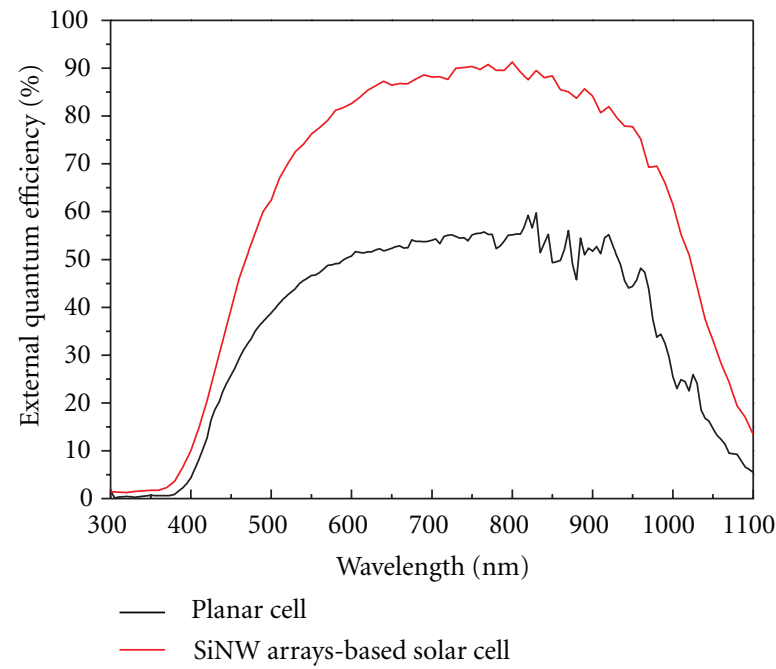

(a)

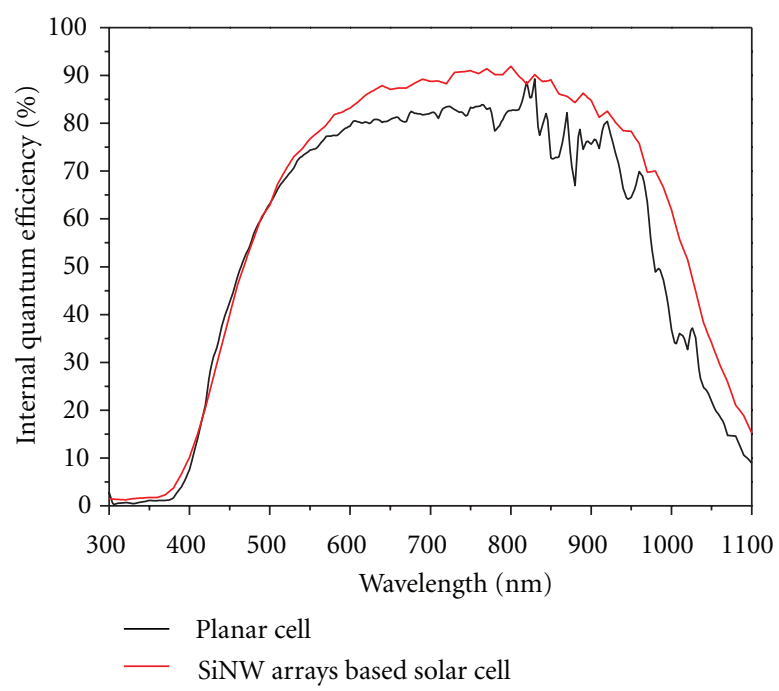

(b)

FIGURE 6: (a) IQE and (b) EQE as a function of the wavelength for the planar solar cell and the Si NW solar cell.

have lower reflectance in our investigated length range. A new method to make front electrodes on Si NW arraysbased solar cells through evaporating $\mathrm{Ag}$ around the area of Si NW arrays has been developed to make a compact contact. By a simple phosphorus diffusion to form the emitter in such samples, the Si NW solar cell with excellent AR property exhibits a higher power conversion efficiency of $8.84 \%$. The analysis of reflectance and quantum efficiency suggest that the improved device performance is attributed to the excellent AR property of the Si NW arrays. To further improve the performance of Si NW arrays-based solar cell, many process parameters, for example, surface passivation, front and rear electrode design, Si NW arrays morphology, and phosphorus diffusion, should be optimized. 


\section{Acknowledgments}

This work is supported by National Natural Science Foundation of China (Grant nos. 60906002 and 50832006), National Key Technology R\&D Program (Grant no. 2011BAE03B13), and Innovation Team Project of Zhejiang Province (Grant no. 2009R50005).

\section{References}

[1] X. Duan, Y. Huang, R. Agarwal, and C. M. Lieber, "Singlenanowire elecctrically driven lasers," Nature, vol. 421, no. 6920, pp. 241-245, 2003.

[2] B. Tian, X. Zheng, T. J. Kempa et al., "Coaxial silicon nanowires as solar cells and nanoelectronic power sources," Nature, vol. 449, no. 7164, pp. 885-889, 2007.

[3] E. C. Garnett and P. Yang, "Silicon nanowire radial p-n junction solar cells," Journal of the American Chemical Society, vol. 130, no. 29, pp. 9224-9225, 2008.

[4] K. Q. Peng and S. T. Lee, "Silicon nanowires for photovoltaic solar energy conversion," Advanced Materials, vol. 23, no. 2, pp. 198-215, 2011.

[5] H. Lu and C. Gang, "Analysis of optical absorption in silicon nanowire arrays for photovoltaic applications," Nano Letters, vol. 7, no. 11, pp. 3249-3252, 2007.

[6] S. K. Srivastava, D. Kumar, P. K. Singh, M. Kar, V. Kumar, and M. Husain, "Excellent antireflection properties of vertical silicon nanowire arrays," Solar Energy Materials and Solar Cells, vol. 94, no. 9, pp. 1506-1511, 2010.

[7] W. Q. Xie, J. I. Oh, and W. Z. Shen, "Realization of effective light trapping and omnidirectional antireflection in smooth surface silicon nanowire arrays," Nanotechnology, vol. 22, no. 6, Article ID 065704, 2011.

[8] K. Peng, Y. Xu, Y. Wu, Y. Yan, S. T. Lee, and J. Zhu, "Aligned single-crystalline Si nanowire arrays for photovoltaic applications," Small, vol. 1, no. 11, pp. 1062-1067, 2005.

[9] H. Fang, X. Li, S. Song, Y. Xu, and J. Zhu, "Fabrication of slantingly-aligned silicon nanowire arrays for solar cell applications," Nanotechnology, vol. 19, no. 25, Article ID 255703, 2008.

[10] D. Kumar, S. K. Srivastava, P. K. Singh, M. Husain, and V. Kumar, "Fabrication of silicon nanowire arrays based solar cell with improved performance," Solar Energy Materials and Solar Cells, vol. 95, no. 1, pp. 215-218, 2011.

[11] H. Li, R. Jia, C. Chen et al., "Influence of nanowires length on performance of crystalline silicon solar cell," Applied Physics Letters, vol. 98, no. 15, Article ID 151116, 2011.

[12] C. Chen, R. Jia, H. Yue et al., "Silicon nanowire-array-textured solar cells for photovoltaic application," Jounral of Applied Physics, vol. 108, Article ID 094318, 5 pages, 2010.

[13] Y. Wang, V. Schmidt, S. Senz, and U. Gösele, "Epitaxial growth of silicon nanowires using an aluminium catalyst," Nature Nanotechnology, vol. 1, no. 3, pp. 186-189, 2006.

[14] O. Gunawan and S. Guha, "Characteristics of vapor-liquidsolid grown silicon nanowire solar cells," Solar Energy Materials and Solar Cells, vol. 93, no. 8, pp. 1388-1393, 2009.

[15] V. Sivakov, F. Heyroth, F. Falk, G. Andrä, and S. Christiansen, "Silicon nanowire growth by electron beam evaporation: kinetic and energetic contributions to the growth morphology," Journal of Crystal Growth, vol. 300, no. 2, pp. 288-293, 2007.

[16] C. M. Hsu, S. T. Connor, M. X. Tang, and Y. Cui, "Waferscale silicon nanopillars and nanocones by Langmuir-Blodgett assembly and etching," Applied Physics Letters, vol. 93, no. 13, Article ID 133109, 2008.

[17] C. Yang, G. Zhang, D. Y. Lee et al., "Self-assembled wire arrays and ITO contacts for silicon nanowire solar cell applications," Chinese Physics Letters, vol. 28, no. 3, Article ID 035202, 2011.

[18] K. Peng, Y. Wu, H. Fang, X. Zhong, Y. Xu, and J. Zhu, "Uniform, axial-orientation alignment of one-dimensional singlecrystal silicon nanostructure arrays," Angewandte Chemie, vol. 44, no. 18, pp. 2737-2742, 2005.

[19] K. Q. Peng, J. Hu, Y. Yan et al., "Fabrication of singlecrystalline silicon nanowires by scratching a silicon surface with catalytic metal particles," Advanced Functional Materials, vol. 16, no. 3, pp. 387-394, 2006.

[20] K. Peng, H. Fang, J. Hu et al., "Metal-particle-induced, highly localized site-specific etching of Si and formation of single-crystalline Si nanowires in aqueous fluoride solution," Chemistry, vol. 12, no. 30, pp. 7942-7947, 2006.

[21] K. Peng, A. Lu, R. Zhang, and S. T. Lee, "Motility of metal nanoparticles in silicon and induced anisotropic silicon etching," Advanced Functional Materials, vol. 18, no. 19, pp. 3026-3035, 2008.

[22] Z. Huang, N. Geyer, P. Werner, J. De Boor, and U. Gösele, "Metal-assisted chemical etching of silicon: a review," Advanced Materials, vol. 23, no. 2, pp. 285-308, 2011. 

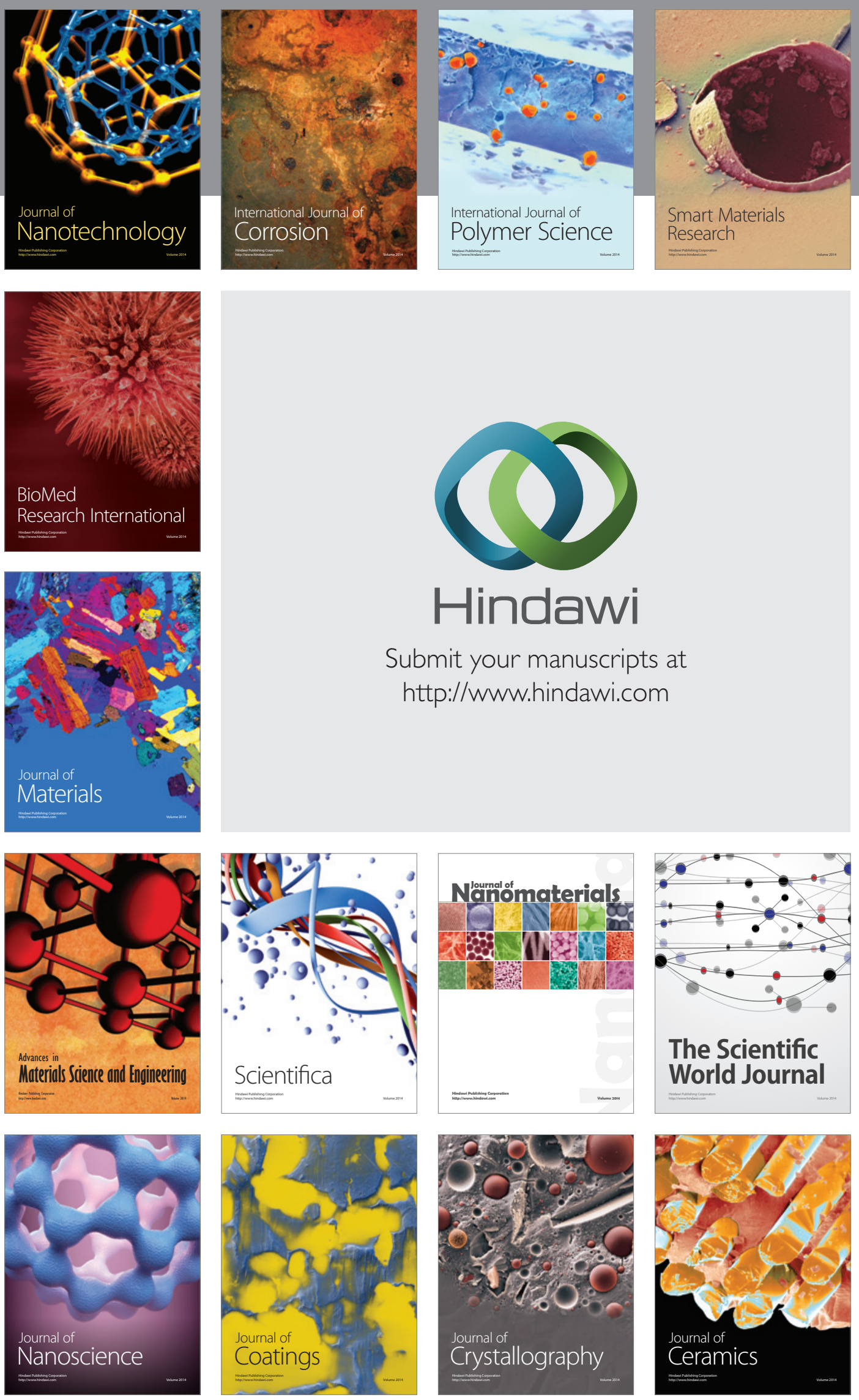

The Scientific World Journal

Submit your manuscripts at

http://www.hindawi.com

\section{World Journal}

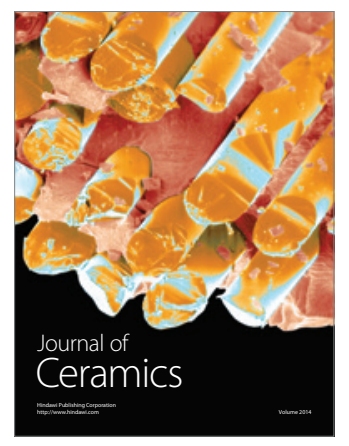

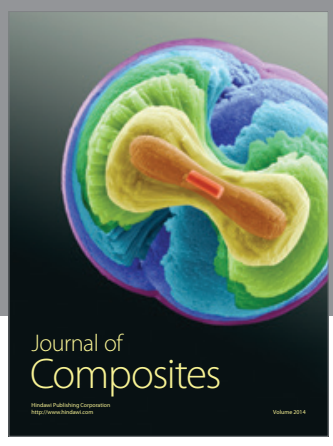
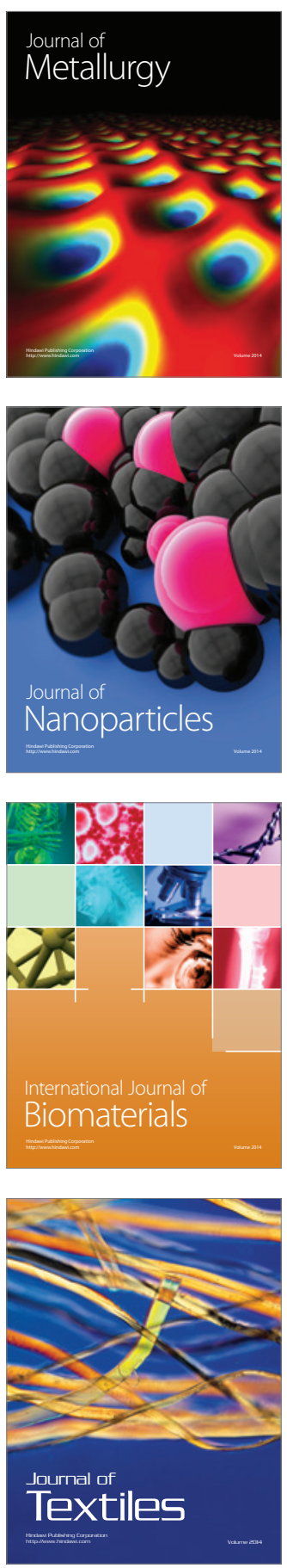